\title{
The technology of gold-containing concentrates recovery from the coal combustion products of the Yerkovetskoye brown coal deposit (the Amur Region, Russia)
}

\author{
Anatoly Sorokin ${ }^{* 1,2}$ and Oleg Ageev ${ }^{1}$ \\ ${ }^{1}$ Amur Scientific Center, Far Eastern Branch of the Russian Academy of Sciences, Blagoveshchensk, \\ Russia \\ ${ }^{2}$ Institute of Geology and Nature Management Far Eastern Branch of the Russian Academy of \\ Sciences, Blagoveshchensk, Russia
}

\begin{abstract}
Annotation. The results of experimental research of the native gold distribution in the coal combustion products $(\mathrm{CCP})$ obtained out of the brown coals of the Yerkovetskoye deposit combustion material in the experimental technological complex "Amur" (ETC "Amur") are described in the article. The technology of the formation of slag, fly ash and products of wet cleaning of flue gases in the process of various combustion modes of coal combustion is examined. The possibility of the obtaining of enriched gold-containing concentrate by gravity and magnetic methods from the brown coal combustion products and extraction of native gold out of the concentrate is shown.
\end{abstract}

\section{Object of study}

Yerkovetskoye brown coal deposit was chosen as the object of research. It is located in the Amur region, $75 \mathrm{~km}$ east of Blagoveshchensk. It is operated on the southern outskirts, in the "Yuzhny" quarry, where a coal layer up to $9 \mathrm{~m}$ thick is discovered with interlayers and lenses (up to $10 \mathrm{~cm}$ ) of clays, aleurites and tuffs. Upper Miocene sands and clays and Quaternary sediments are found in the supra-angular part. Coals of the deposit are brown coals, technological group $2 \mathrm{~B}$, are of the medium degree of coalification, dense with interlayers of loose. The quality of the coals (in \%) is the following: humidity 36.5 , ash content 17.5 , volatile yield 44 , and sulfur content 0.3 . The lowest heat of combustion is 12.81 MJ / kg. The balance reserves of 1077.8 million tonnes. [1]

\section{Technology of the CCP obtaining}

To study the process of transfer and distribution of gold and other valuable elements in the products of coal combustion (furnace slag, fly ash, smoke and technogenic water) formed during the coal combustion, the Amur Scientific Center (AmurSC) FEB RAS created an

\footnotetext{
*Corresponding author: amurnc@ascnetl.ru
} 
Experimental-Technological Complex "Amur "(ETC" Amur ") in 2017 [2]. The particular qualities of the complex are the autonomous production of $\mathrm{CCP}$ at the coal combustion stage, controlled combustion of fuel, the presence of an afterburner chamber for volatile carbon compounds, and a combined technology for cleaning flue gases and man-made water from harmful and toxic impurities.

Brown coals of the Yerkovetskoye deposit were investigated. The gold content in the initial products of combustion of brown coals (Table 1) is determined by neutron activation analysis (NAA) at the Institute of Chemistry, FEB RAS, the gold content in technogenic water is determined by atomic-adsorption analysis (AAA), at the Institute of Geology and Nature Management (IGNM) FEB RAS [3].

Table 1. Average content of gold in brown coal combustion products.

\begin{tabular}{|c|c|c|c|c|}
\hline & Coal combustion products & Au content & NAA & AAA \\
\hline 1. & Furnace slag source & $\mathrm{g} / \mathrm{t}$ & 0,25 & - \\
\hline 2. & $\begin{array}{c}\text { Products of flue gases (fly ash) } \\
\text { coarse (dry) cleaning }\end{array}$ & $\mathrm{g} / \mathrm{t}$ & 0,30 & - \\
\hline 3. & $\begin{array}{c}\text { Products of thin (wet) cleaning of the } \\
\text { flue gas (sludge) }\end{array}$ & $\mathrm{g} / \mathrm{t}$ & 1,71 & - \\
\hline 4. & Technogenic water & $\mathrm{mg} / 1$ & - & 0,00030 \\
\hline
\end{tabular}

The graph (Fig. 1.) shows the increased gold content in flue gas cleaning products in comparison with furnace slags. The transformation of gold during the combustion process and the form of its transportation with the flue gases has not been investigated.

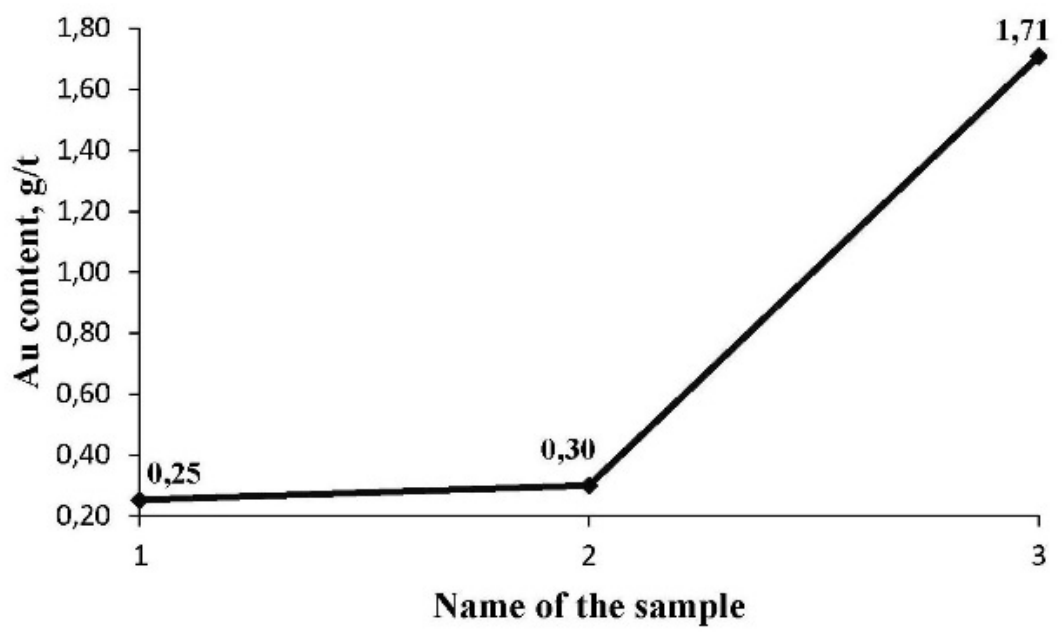

Fig. 1. Graph of correlation, gold content in the samples, performed by neutron activation analysis. Sample name: 1 - slag initial; 2 - products of coarse (dry) cleaning of flue gases; 3 - products of thin (wet) cleaning of flue gases. 


\section{Preparation of gold-containing concentrate from coal combustion products (CCP).}

To discover and study the forms and features of finding native gold in coal combustion products (CCP), the AmurSC FEB RAS developed a technology of gravity and magnetic enrichment of the CCP for obtaining gold-containing concentrate.

\subsection{Enrichment of combustion slag}

The slag, which was formed from the combustion chamber, formed as a result of coal combustion by layer method, was crushed on a jaw crusher up to $1 \mathrm{~mm}$ fraction, then it passed through a wet magnetic separator WMS-0.1. The resulting magnetic fraction (metal oxides) can be a raw material for the metallurgical industry.

The non-magnetic fraction (mixture of underburn, slag, sand, clay, etc.) was enriched by the gravity method (Fig. 2). To separate the non-magnetic fraction of underburn and light particles from the composition, a slightly inclined gateway of rectangular cross-section was used. The drug mats, which allow creating a turbulent flow in the near-bottom layers and retaining the heavy particles that are deposited on the bottom, were laid at the bottom of the gateway. The isolated light fraction (underburn) is the raw material for the production of coal briquettes.

The heavy fraction, after grinding (up to $-0.1 \mathrm{~mm}$ ), was fed to the concentration table SKO-0.5. On the table were received the final products of enrichment - concentrate and table tails. Tails of the table - a light enrichment fraction (purified from underburning, iron oxides and other heavy elements) are ready raw materials for use in road construction and the production of building materials.

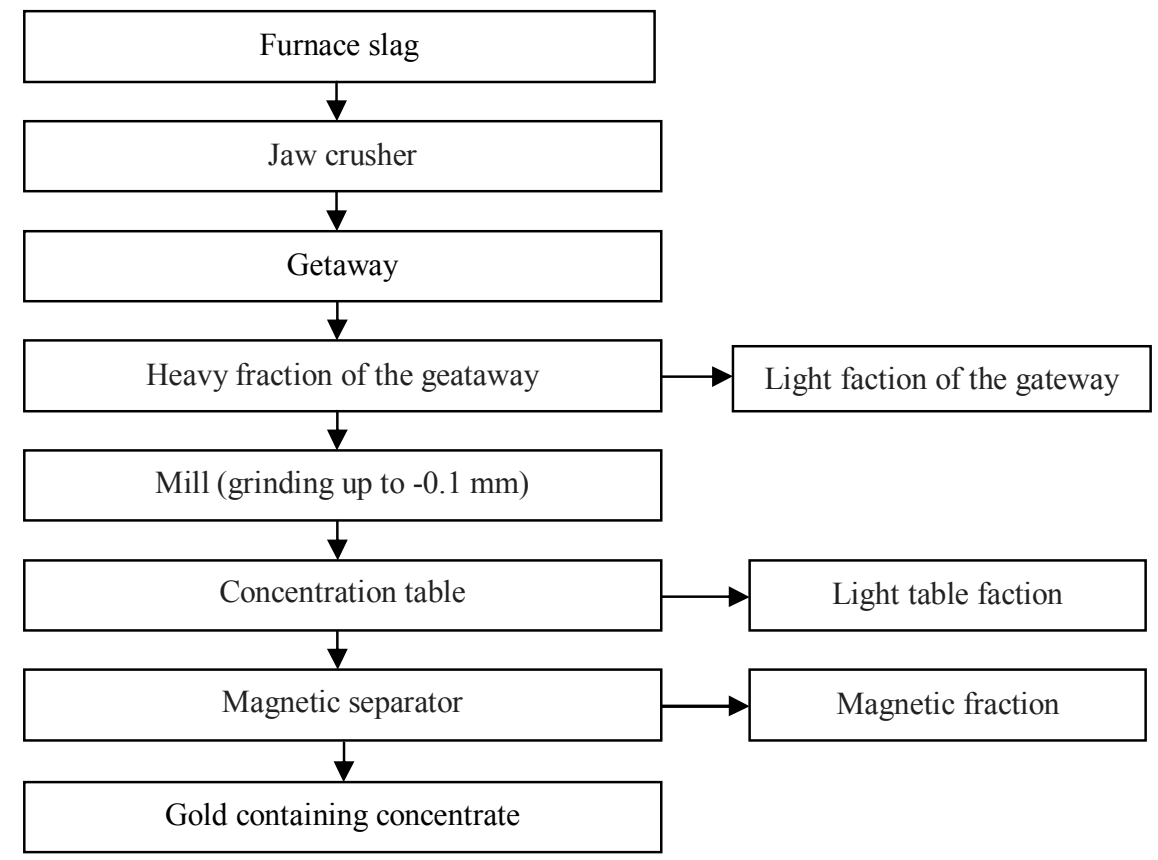

Fig. 2. Technological scheme for gold-containing concentrate obtaining from combustion slag. 
Gold content in furnace slag in enrichment products was analyzed by the assay-analytical method in assay laboratory of AmurSC FEB RAS (Table 2).

Table 2. Gold content in furnace slag beneficiation products

\begin{tabular}{|c|c|}
\hline Flue slag enrichment products & Au content, g/t \\
\hline Heavy fraction of table (concentrate) & 8,31 \\
\hline Light table faction & 0,05 \\
\hline Magnetic fraction & 0,88 \\
\hline
\end{tabular}

\subsection{Fly ash enrichment}

A two-section ash collector is used in the ETC "AMUR" for rough cleaning of smoke from medium size dust and particles (up to 10 microns). The principle of the ash collector is dry gravity enrichment, based on the rate difference of incidence of the particles, having different density or fineness in the gas flow. There is a significant slowing down of the particle flow in the ash collector, which facilitates the precipitation of all particles. To adjust this process, as well as to obtain the desired fraction of fly ash, adjusting flaps are used. Fly ash accumulates in the hoppers of the ash collector and is periodically removed.

The resulting fly ash (Fig. 3) is distributed on a sieve analyzer A-50 by size classes on fractions from 0.5 to $0.04 \mathrm{~mm}$. After that, each faction is enriched individually. The magnetic fraction was extracted on the wet magnetic separator then the non-magnetic fraction is enriched on the concentration table (Fig. 3).

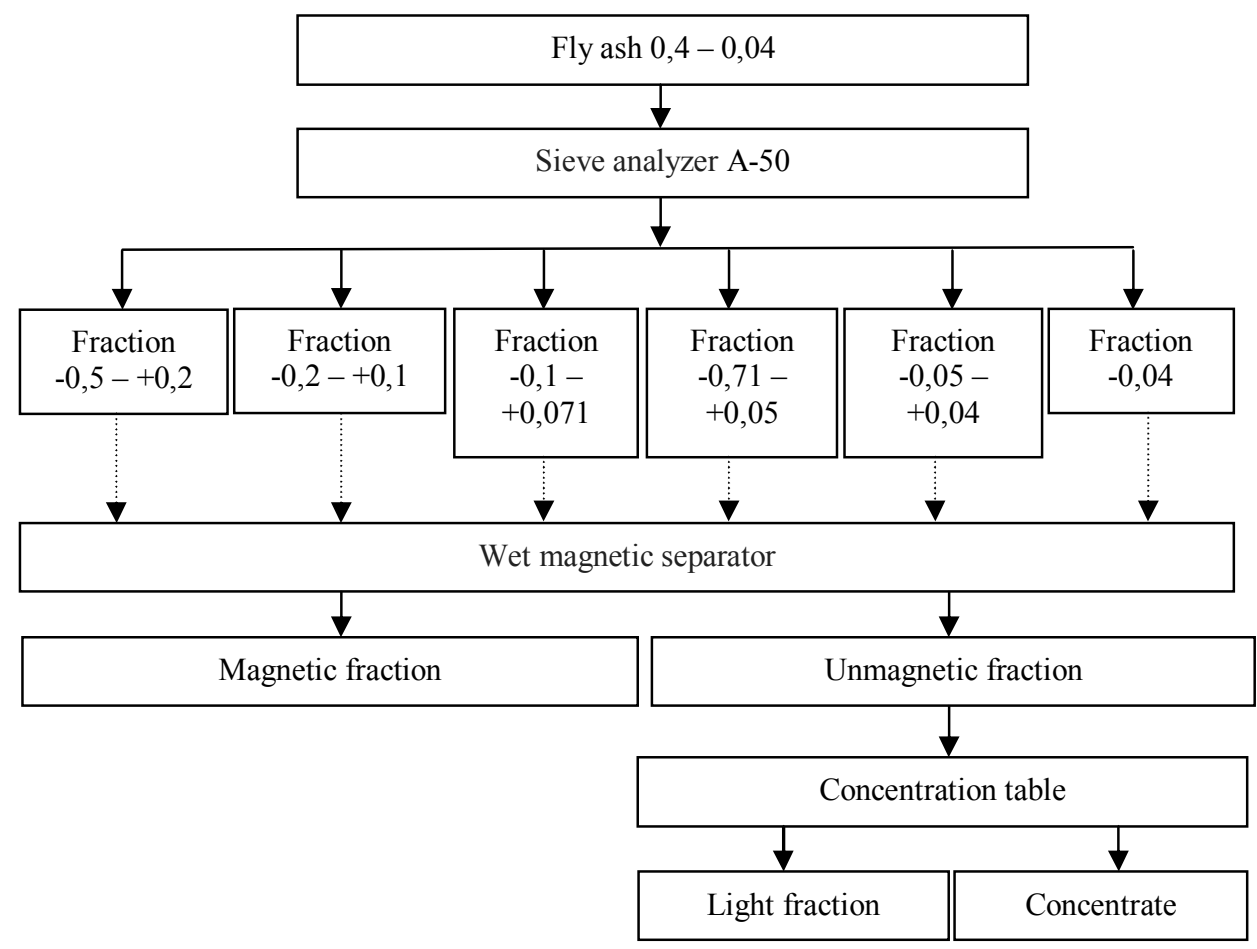

Fig. 3. Chart of fly ash beneficiation for obtaining gold concentrate. 
Gold content in furnace fly ash in enrichment products was analyzed by the assay-analytical method in assay laboratory of AmurSC FEB RAS (Table 3).

Table 3. Gold content in the products of fly ash enrichment.

\begin{tabular}{|c|c|}
\hline Products of the fly ash enrichment & Au content, $\mathrm{g} / \mathrm{t}$ \\
\hline Heavy fraction of the table (concentrate) & 2,25 \\
\hline Light fraction of the table & 0,93 \\
\hline Technogenic water sediment (filtration) & 1,54 \\
\hline
\end{tabular}

The resulting gold-bearing concentrate was studied by the gold panning method at the Institute of Geology and Geochemistry of the Far East Branch of the Russian Academy of Sciences, with the release of particles of native gold (Fig. 4, 5).

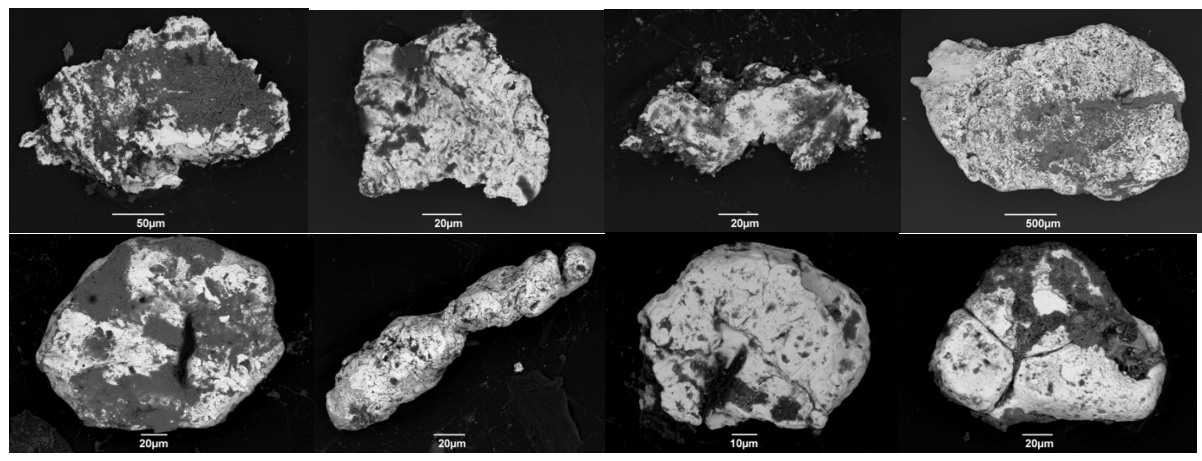

Fig. 4. Native gold extracted from combustion slag.

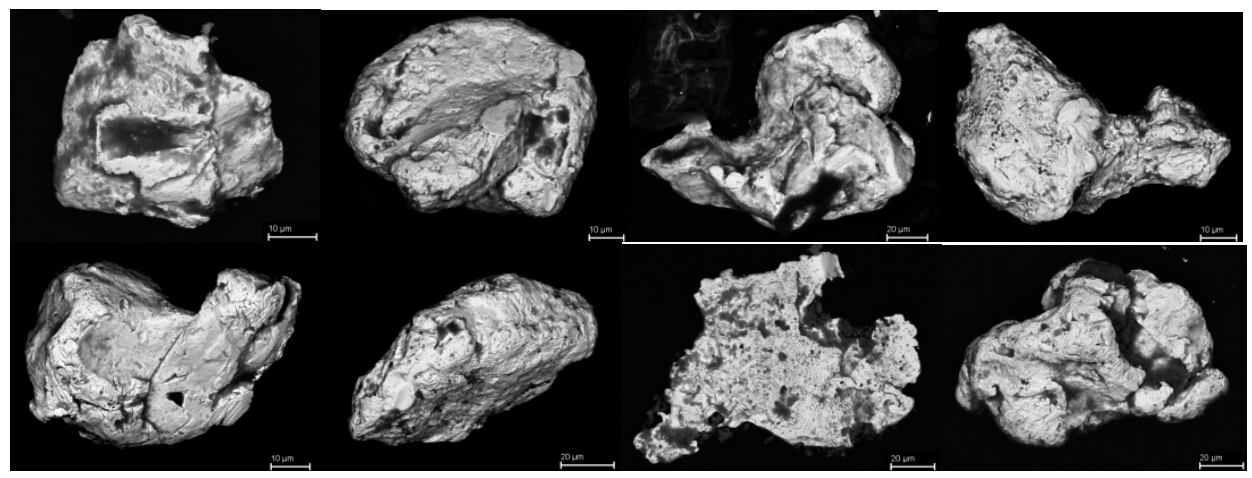

Fig. 5. Native gold in the fly ash.

As a result of magnetic and gravity enrichment we've obtained the following:

1) Magnetic fraction consisting of ferrous compounds in form of magnetite and paramagnetic compounds of heavy metals. The magnetic fraction is the raw material for the metallurgical industry.

2) Light fraction (table tails), which is an aluminosilicate form of silicon, can be used as raw material for cements and besclinker binders, concretes (heavy, light, cellular), porous aggregates, silicate, ceramic, heat-insulating and other materials.

3) The heavy non-metallic fraction (table concentrate) contains a number of elements, including native gold.

The gas stream purified of dust (more than 10 microns in size) and as well as the volatile products of fuel combustion consisting of hot gases containing oxides of carbon, 
nitrogen, sulfur, and water vapor, is extracted from the ash collector into the scrubber by the smoke exhauster.

Main function of the scrubber is the deep cleaning of the flue gasses from the impurities.

The operating principle of the action of wet cleaning is based on the intensive crushing of the irrigating liquid with a dusty gas stream moving at high speed. As a result of this interaction, dust particles penetrate into the liquid upon impact, and in the form of sludge are continuously discharged to the filter unit for cleaning.

\subsection{Enrichment of the products of the wet flue gas cleaning}

The flue gases wet cleaning output is the sludge, obtained as a result of purification of technogenic water by a coarse filter, was not subjected to gravity enrichment (due to physical limitations of the method).

The sludge was washed in bromoform, divided into fractions: magnetic, electromagnetic, non-magnetic heavy and non-magnetic light fraction, which were investigated by the gold panning method using microchemical reactions and the immersion method with the release of particles of native gold (IGNM FEB RAS) (Fig. 6).

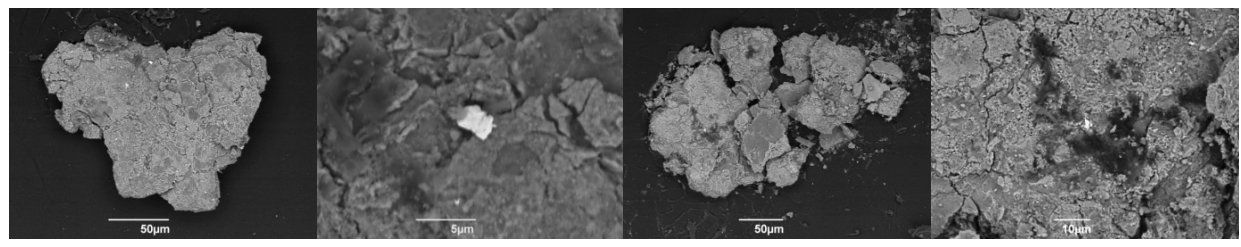

Fig. 6. Gold conglomerates extracted from sludge with the presence of microparticles of gold (white phase).

\section{Conclusion}

The conducted research of slags and fly ash showed the presence of significant amount of native gold, which can be concentrated by gravity and magnetic methods.

Only by combining physical methods of enrichment with hydrometallurgical operations the effective gold extraction out of the CCP can be achieved. The "chemical concentrate" is obtained as the result of this combination. [4-10].

Finished raw materials for various industries were obtained in the process of gravity and magnetic enrichment of CCP: magnetic fraction - raw materials for the metallurgical industry $[11,12]$; light fraction - "underburn" - raw materials for the production of coal briquettes [13, 14]; light fraction of the concentration table - raw materials for road construction and production of building materials [15].

\section{References}

1. Mineral and raw materials base of the Amur Region at the turn of the century / I. A. Vasiliev et. al.; Ed. I. A.Vasiliev. - Blagoveshchensk: Committee of Natural Resources Amur region, P. 168 (2000).

2. Sorokin A. P., Ageev O. A. Formation of the coal combustion products in the experimental and technological complex "Amur" // Complex use of the potential of stone and brown coals and creation of combined ecologically safe technologies for their 
development: All-Russian Conf. with intern. participation: reports. Blagoveshchensk: AmurSC FEB RAS, P. 100-102 (2017).

3. Ageev O. A., Yudakov A.A., Ivannikov S.I., Zubenko I.A. Distribution of macroelements and gold in coal combustion products (experimental results) // Complex use of the potential of stone and brown coals and creation of combined ecologically safe technologies for their development: All-Russian Conf. with intern. participation: reports. Blagoveshchensk: AmurSC FEB RAS, P. 129-132 (2017).

4. L. Canada, T. Heput, E. Ardelian. Methods for recovering precious metals from industrial waste // IOP Conference Series: Materials Sciences and Engineering. IOP Publishing. 106(1) P. 12-20 (2016).

5. J. He, A. Kappler. Recovery of precious metals from waste streams //[Microbial Biotechnology] 10(5) P. 1194-1198 (2017).

6. Prafulla Kumar Sahoo, Kangjoo Kim, M. A. Powell, Sk. Md. Equeenuddin. Recovery of metals and other beneficial products from coal fly ash: a sustainable approach for fly ash management // International Journal of Coal Science \& Technology. 3(3) P. 267-283 (2016).

7. L. Tolhurst. Commercial Recovery of Metals from Coal Ash. Lucid Insight Ltd, Oxford, UK, Conference: (2015) World of Coal Ash [www.worldofcoalash.org]

8. K.V. Ramesh, D. Sandhaya Rani. Coal-Gold Agglomeration: An Alternative Separation Process in Gold Recovery. Conference: Chemical Engineering Letters. At: Visakhapatnam, 1(1) P. 39-40 (2015).

9. S. Dai, V.V. Seredin, C.R. Ward, J. Jiang, C. Zhao. Composition and modes of occurrence of minerals and elements in coal combustion products derived from high-Ge coals // International Journal of Coal Geology. 121(1) P. 79-97 (2014).

10. S. Yu. Bratskaya, A.S. Volk, V.V. Ivanov, A. Yu. Ustinov, V.A. Avramenko. A new approach to precious metals recovery from brown coals: Correlation of recovery efficacy with the mechanism of metal-humic interactions // Geochimica et Cosmochimica Acta. 73. Is. 11(1). P. 3301-3310 (2009).

11. A.S. Shoumkova. Magnetic separation of coal fly ash from Bulgarian power plants // Waste Management and Research. 29(10) P. 1078-1089 (2009).

12. G.C. Han1, N. I. Um, U. Kwangsuk, H. C. Cho, J. Ahn. Recovery of ferromagnetic material by wet magnetic separation in coal bottom ash // Geosystem Engineering. 12(1) P. 26-30. (2009).

13. H. Carrasco, H. Sarper. Developing Engineered Fuel (Briquettes) using Fly Ash from the Aquila Coal-fired Power Plant in Cañon City and locally available Biomass Waste. Final Report. Colorado State University - Pueblo.

14. USOO.5916826A United States Patent (19)11. Patent Number: 5,916,826 White (45). Pelletizing and briquetting of coal fines using binders produced by liquefaction of biomass. Date of Patent: Jun.29, (1999).

15. I. Kula, A. Olgun, V. Sevinc, Y. Erdogan. An investigation on the use of tincal ore waste, fly ash, and coal bottom ash as Portland cement replacement materials // Cement and Concrete Research. 32(2). P. 227-232. (2002). 